\title{
Characterization and Valuation of a Clay Soil Sampled in Londéla-Kayes in the Republic of Congo
}

\section{Roger Makosso Voula1, Flora Zita Mpissi Diamouangana ${ }^{1,2 *}$, Joseph-Marie Moutou ${ }^{1,2}$, Vivien Igore Banzouzi Samba1, Mozalin Paul Foutou' ${ }^{1}$, Julien Placide Ngoma1}

${ }^{1}$ Laboratoire de Chimie minérale et Appliquée, Faculté des sciences et Techniques, University Marien Ngouabi, Brazzaville, Congo ${ }^{2}$ Ecole Normale Supérieure, University Marien Ngouabi, Brazzaville, Congo

Email: ${ }^{\star}$ florajullie@gmail.com

How to cite this paper: Voula, R.M., Diamouangana, F.Z.M., Moutou, J.-M., Samba, V.I.B., Foutou, M.P. and Ngoma, J.P. (2021) Characterization and Valuation of a Clay Soil Sampled in Londéla-Kayes in the Republic of Congo. Journal of Minerals and Materials Characterization and Engineering, 9, 117-133.

https://doi.org/10.4236/jmmce.2021.92009

Received: November 27, 2020

Accepted: February 7, 2021

Published: February 10, 2021

Copyright $\odot 2021$ by author(s) and Scientific Research Publishing Inc. This work is licensed under the Creative Commons Attribution International License (CC BY 4.0)

http://creativecommons.org/licenses/by/4.0/

\begin{abstract}
In order to characterize and enhance clay collected in Londéla-kayes in the Republic of Congo, in this work, it was a question of proceeding to the mineralogical, physico-chemical, thermal and geotechnical characterization of this clay. Next, determine the technological properties of fired bricks. For this, various methods were used in particular: X-ray diffraction, infrared spectroscopy, gravimetric thermal analysis and differential thermal analysis, dilatometric analysis, scanning electron microscopy, specific surface and analysis chemical. It appears that, for the mineralogical characterization, kaolinite is the most abundant mineral of this clay. The results of dilatometric analysis have shown that this clay can be fired at low temperatures. The geotechnical characterization showed that it is plastic clay thus exhibiting a high shrinkage. The results of the technological properties of LON1 bricks have shown that this clay cannot be used in the manufacture of fired bricks. The geotechnical properties must be improved by adding additives in order to improve the technological properties of the fired bricks.
\end{abstract}

\section{Keywords \\ Clay, Characterization, Valuation}

\section{Introduction}

Clay refers to any natural material, composed of fine grains, which turns plastic in the presence of suitable water contents and hardens by drying or heating [1]. The latter is mainly used in the ceramic and pharmaceutical industries, in road 
construction, in economic housing and in the chemical industry [2]. In the chemical industry, they initiate certain reactions (cracking of mineral oils or polymerization of certain organic molecules) [3]. The structural determination of a clay, directs towards the use of it. In recent years, our laboratory, which favors applied research, has been interested in some applications of clay raw materials, in particular the field of ceramics and, above all, has worked to determine for many clayey sites in Congo Brazzaville the physico-chemical, thermal and mineralogical compositions as well as geotechnical properties [4] [5] [6] [7] [8]. In Londéla-kayes, clay soils are mainly used by rural populations for the manufacture of fired bricks. The fired brick manufacturing units are functional, but the products obtained are not of good quality. This could be due to the lack of mastery of the technology as well as the quality of the clays used. The resulting bricks break and do not withstand heavy rains. In order to support rural populations in this sector, our work consists of characterizing these clays, determining the technological properties of fired bricks in order to better understand their use. By characterizing and determining the technological properties of fired bricks from the clay sample at the study site, using modern techniques and equipment, this research may provide answers to certain questions of fundamental interest.

\section{Material and Method}

\subsection{Location and Site of Clay Sampling}

The sample was taken in Kayes Bakou in the village of Londéla-kayes district located in the southwest of the Republic of Congo near the border between the Republic of Congo and the Democratic Republic of Congo. Sampling took place during the dry season. The sample taken from this site was named LON1. The GPS coordinates of the sampling site are presented in Table 1.

The GPS coordinates of the study area allowed us to locate the LON1 sample collection site in Figure 1.

\subsection{Experimental Study}

The sample was dried at room temperature, crushed and then sieved at $2 \mathrm{~mm}$. The sieve obtained was subjected to a series of physico-chemical and mineralogical analyzes.

\subsubsection{X-Ray Diffraction}

It was carried out in Abidjan in Ivory Coast at the crystallography laboratory. This analysis allowed us to know the mineralogical of LON1.

Table 1. GPS coordinates of the sampling.

\begin{tabular}{ccc}
\hline Sample & Latitude & Longitude \\
\hline LON1 & $04^{\circ} 44^{\prime} 44.3^{\prime \prime S}$ & $013^{\circ} 31^{\prime} 01.1^{\prime \prime} \mathrm{E}$
\end{tabular}




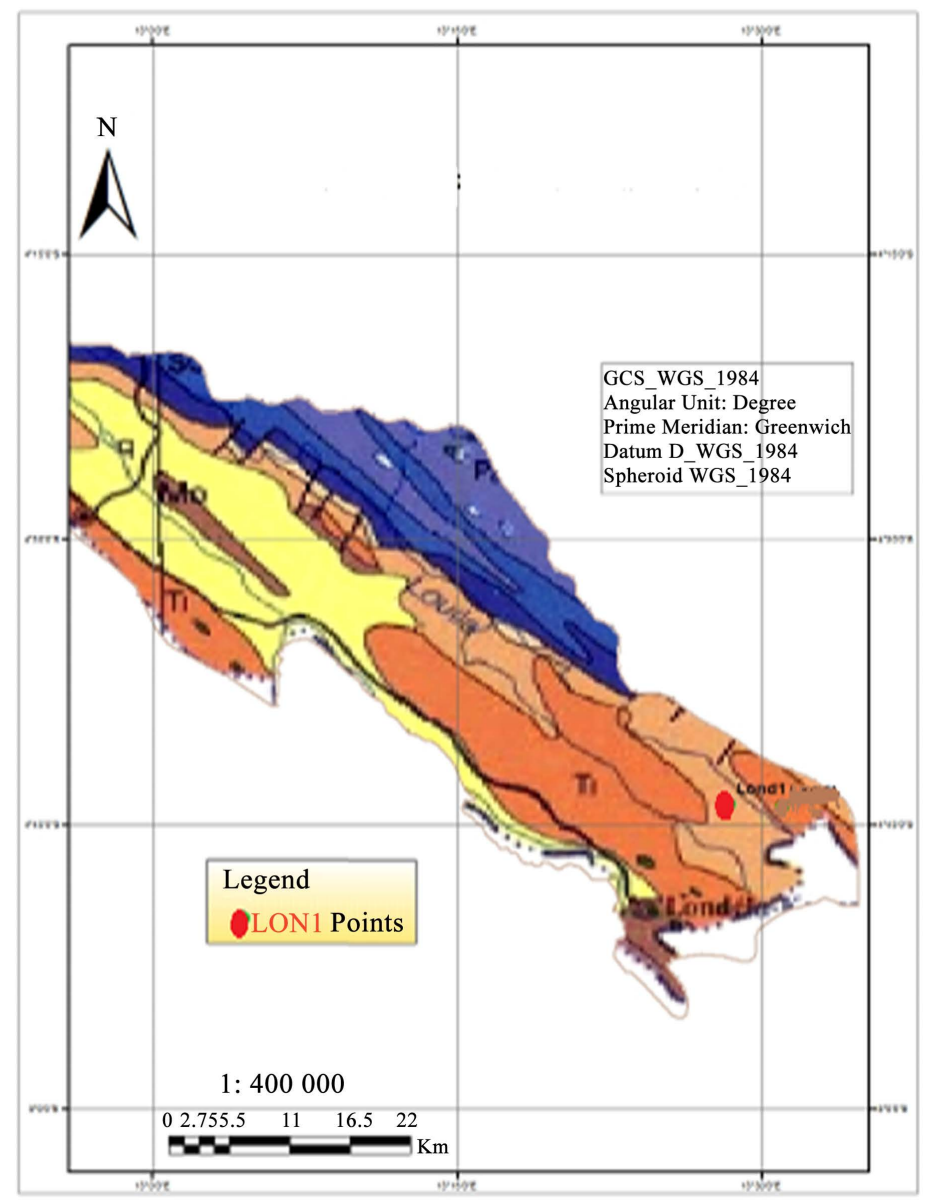

Figure 1. Location of LON1 sampling sites.

\subsubsection{Infrared Spectroscopy}

It was carried out in Cameroon at the Faculty of Science of the University of Yaoundé 1 in the Laboratory of Applied Analytical Chemistry. This technique was used for the determination of the functional groups present in LON1. Each link has characteristic vibrations that allow the types of links to be identified.

\subsubsection{Gravimetric Thermal Analysis and Differential}

Thermal analysis they were carried out in France at the University of Limoge at the Technical Center of ceramic Transfer. These analyzes were made in order to know the behavior of LON1 according to the temperature range going from $0^{\circ} \mathrm{C}$ to $1200^{\circ} \mathrm{C}$.

\subsubsection{Dilatometric Analysis}

It was carried out in France at the University of Limoge at the Technical Center of Ceramic Transfer. It consists of monitoring the sintering ability of LON1 during a thermal cycle over the temperature range from $0^{\circ} \mathrm{C}$ to $1400^{\circ} \mathrm{C}$.

\subsubsection{Scanning Electron Microscopy}

It was performed in China at Fudan University Shanghai in the Physics Applied to Materials Laboratory. This technique allows us to observe the surface mor- 
phology of LON1, then to determine the quality and quantity of the chemical elements present in this soil.

\subsubsection{Chemical Analysis}

The chemical analysis of the major elements was carried out at the Petrographic and Geological Research Center (PGRC) of Nancy in France by the method described by Carignan et al. [9].

\subsubsection{Particle Size Analysis}

It was carried out in Congo Brazzaville in the laboratory of the Building and Public Works Control Offices in the acronym BPWCO. This analysis was carried out to determine the distribution of particles in LON1 by following the recommendations of standards NF P 94-056 and NF P 94-057 [10].

\subsubsection{Atterberg Limits}

They were also carried out in Congo at the Building and Works Control Office in the acronym BWCO. This analysis was carried out to determine the liquidity limits (LL) and the plasticity limits (LP) of LON1 by following the recommendations of standard NF P 94-051 [11].

\subsubsection{Specific Surface}

It was carried out in France at the University of Limoge at the Technical Center of ceramic Transfer (TCC.T) by the BET method. This analysis was carried out to determine the total surface area available in LON1 according to an internal protocol inspired by standard NFISO 9277 [12].

\subsection{Technological Properties}

They were carried out in Congo at the Office for the Control of Buildings and Public Works. The technological properties of LON1 were determined on the test tube according to two steps:

- Production of the test tube: The clay soil samples were dried at $105^{\circ} \mathrm{C}$ in an oven. Grinding and sieving with a 34 modulus $(2 \mathrm{~mm})$ sieve is applied. After weighing a given mass, briquettes are shaped with a mold measuring $4 \mathrm{~cm} \times$ $4 \mathrm{~cm} \times 16 \mathrm{~cm}$. The smallbrickwas air dried for five days.

- Baking: the specimens were baked in an oven at different temperatures $\left(850^{\circ} \mathrm{C}, 900^{\circ} \mathrm{C}, 950^{\circ} \mathrm{C}, 1000^{\circ} \mathrm{C}, 1050^{\circ} \mathrm{C}, 1100^{\circ} \mathrm{C}\right.$ and $\left.1150^{\circ} \mathrm{C}\right)$.

\subsubsection{Linear Shrinkage during Cooking}

The determination of the shrinkage percentages during banking was made by studying the variation in the average length of the strokes recorded on the briquettes between drying and firing. It was determined by the following formula:

$$
R(\%)=\frac{L_{0}-L}{L_{0}} \times 100
$$

With:

$L_{0}$ : Drying length. 
$L$ : Banking length.

$R$ : linear shrinkage during banking.

\subsubsection{Water Absorption}

Water absorption was determined by immersing a baked brick specimen in water for 24 hours. It was determined by the following relation:

$$
\operatorname{Abs}(\%)=\frac{m_{h}-m_{s}}{m_{s}} \times 100
$$

With:

$m_{h}$ : The wet mass of the test specimen after immersion.

$m_{s}$ : The dry mass of the test tube.

Abs: Water absorption.

\subsubsection{Mechanical Resistance}

The determination of the mechanical resistance to bending and compression of fired bricks was carried out with BPWCO according to European standards NBN EN 196-1 and EN 772-1 respectively [13].

\section{Results and Discussion}

\subsection{Diffractogram of the Crude Sample of LON1}

Figure 2 illustrates the diffractogram of the raw sample of LON1.

Analysis of this diffractogram allowed us to identify reflections characteristic of phyllosilicates. The inter-reticular distance corresponding to $\mathrm{d}=7.27 \AA$ is characteristic of kaolinite with its harmonics at $4.27 \AA ; 2.38 \AA$ [14]. The presence of kaolinite in LON1 can be explained by the climate encountered in the Republic of Congo, which is predominantly humid tropical favoring very extensive weathering of rocks. In fact, the formation of clays is linked to the physicochemical and biological alteration that affects the bedrock. In Congo Brazzaville, the clays are mainly made up of kaolinite [5] [6] [8]. The inter-reticular distance corresponding to $d=10.30 \AA$ is characteristic of illite [14]. The octahedral layer in illite is made up of Iron or Magnesium; that of LON1 could contain iron

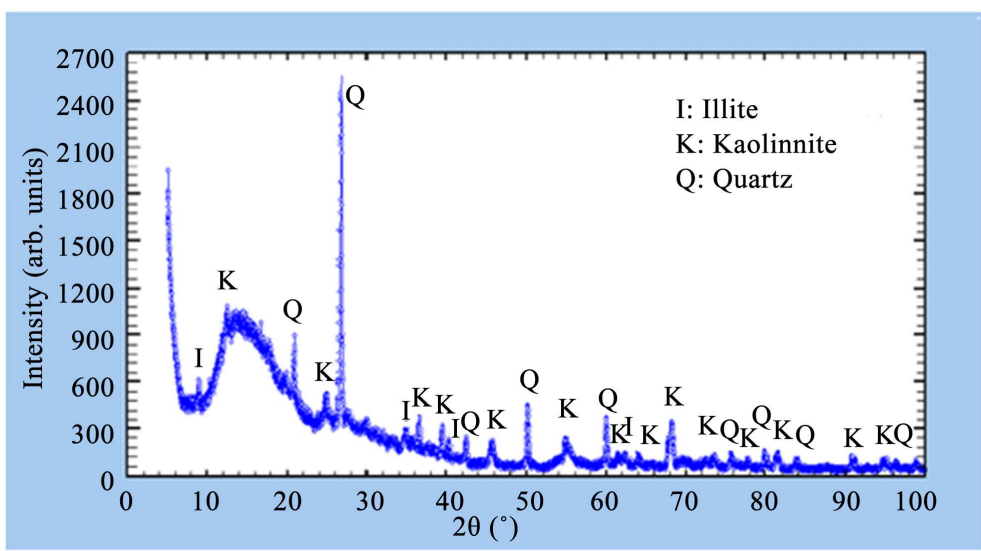

Figure 2. Diffractogram of the raw sample of LON1. 
because the naked eye observation of LON1 shows a red coloration. As an associated mineral, characteristic reflections detected at $3.59 \AA$; $3.34 \AA$; $2.14 \AA$; 1.81 $\AA ; 1.26 \AA ; 1.20 \AA ; 1.15 \AA$ and $1.03 \AA$ correspond to the peaks of quartz. Quartz is the most common mineral found in clay soils.

\subsection{IR Spectrum of Raw Sample LON1}

Figure 3 illustrates the infrared spectrum of LON1.

Analysis of this spectrum allowed us to identify the absorption bands located around $3694.11 \mathrm{~cm}^{-1}, 3621.33 \mathrm{~cm}^{-1}$ and $911.63 \mathrm{~cm}^{-1}$. These bands are attributable to the hydroxyl group $\mathrm{OH}$ characterizing the presence of dioctahedral minerals, in particular Kaolinite [15]. This is in agreement with the results of XRD which revealed the presence of kaolinite. On the other hand, the absorption bands located around $1026.24 \mathrm{~cm}^{-1}, 100.24 \mathrm{~cm}^{-1}$, correspond to the elongation vibrations of $\mathrm{Si}-\mathrm{O}$ also characterizing the presence of Kaolinite [15]. The band observed around $795.89 \mathrm{~cm}^{-1}$ may correspond to the different modes of vibration of the Si-O-Fe bond characteristic of illite [15]. The absorption bands located around $778.70 \mathrm{~cm}^{-1}, 692.54 \mathrm{~cm}^{-1}, 776.96 \mathrm{~cm}^{-1}, 691.78 \mathrm{~cm}^{-1}$ may correspond to quartz [16]. All peaks between 600 and $400 \mathrm{~cm}^{-1}$ correspond to angular deformations of $\mathrm{Si}-\mathrm{O}-\mathrm{M}$ bonds $(\mathrm{M}=\mathrm{Al}, \mathrm{Mg}, \mathrm{Fe}, \mathrm{Li})$ [14].

\subsection{Differential and Thermogravimetric Analysis}

Figure 4 gives the ATG/ATD curves for LON1 clay.

Analysis of these results shows that the ATG curve shows an overall weight loss at $1200^{\circ} \mathrm{C}$ of $7.7 \%$ which mainly breaks down into 3 steps:

- Ambient at $150^{\circ} \mathrm{C}$ characteristic of an endothermic phenomenon with a maximum at $70^{\circ} \mathrm{C}$ : It would result from the departure of residual humidity (loss of mass of 1.5\%), therefore from the desorption of the physically adsorbed water. The results of the ATG/ATD of the clay soil of LOUTETE show us a mass loss of $1.16 \%$ with a maximum at $130^{\circ} \mathrm{C}$ [8]. In view of the results of LON1, the increase in mass loss may be due to the presence of illite which is a 2:1 clay species reported by the XRD

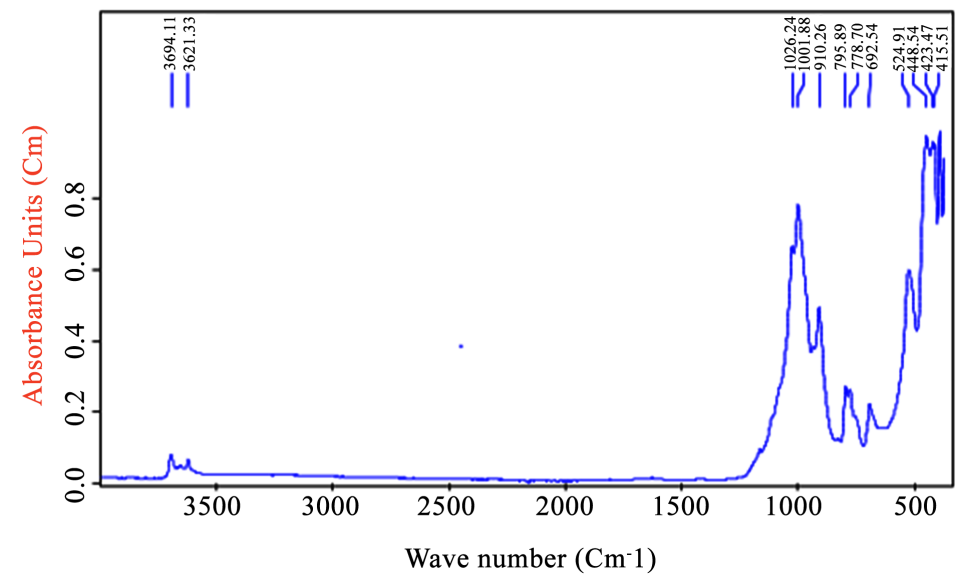

Figure 3. Infrared spectrum of LON1. 


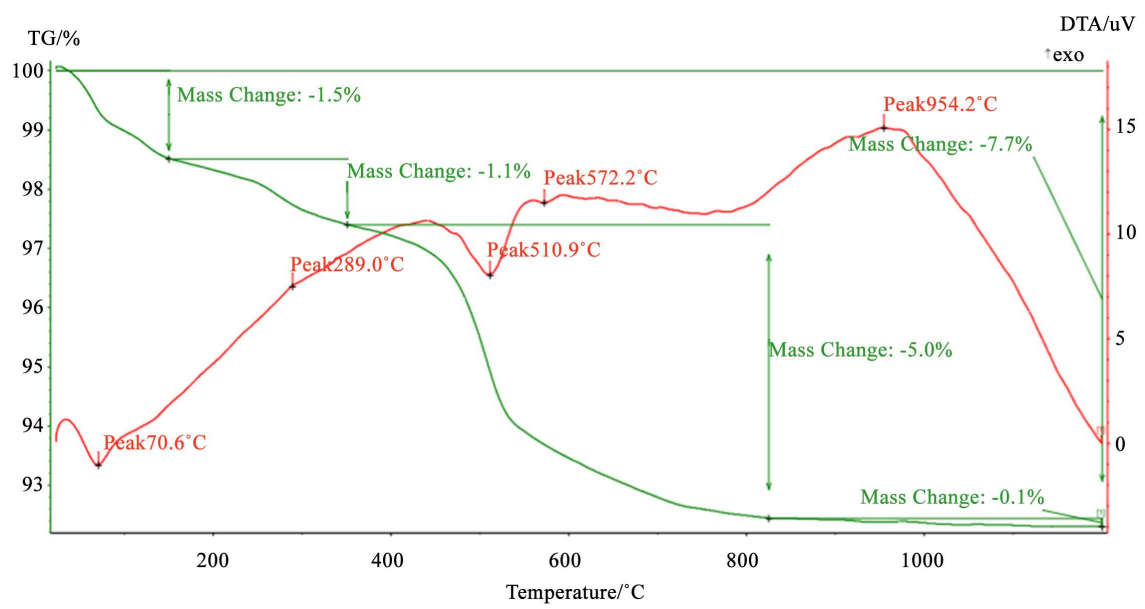

Figure 4. ATG (green)/ATD (red) curves of LON1.

- Between $150^{\circ} \mathrm{C}$ and $350^{\circ} \mathrm{C}$ : a very weakly exothermic behavior is observed with a mass loss of $1.1 \%$ which may be due to the probable decomposition of weak organic residues, the shoulder at around $289^{\circ} \mathrm{C}$ would correspond to the expulsion of water bound to exchangeable stocks in illite.

- Between $350^{\circ} \mathrm{C}$ and $825^{\circ} \mathrm{C}$ : there is an endothermic phenomenon with characteristic peaks at $511^{\circ} \mathrm{C}$ and $572^{\circ} \mathrm{C}$ which can be explained respectively by the dehydroxylation of 1:1 clays and therefore of kaolinite as indicated by the XRD with a loss of mass of $5.0 \%$ deduced by the ATG curve [17] and by the transformation of quartz (passage from the $\alpha$ phase to $\beta$ ).

Above $825^{\circ} \mathrm{C}$, the ATG curve shows a low loss in mass (0.1\%). The ATD curve for its part reveals an exothermic peak around $954^{\circ} \mathrm{C}$, characteristic of the structural reorganization of metakaolinite [14].

\subsection{Dilatometric Analysis}

Figure 5 shows the dilatometric curve recorded for LON1.

We observe on this curve, a weak expansion of a few tenths of a percentage at most below $450^{\circ} \mathrm{C}$ with a rate of $0.05 \%$. The dropout with sudden expansion again by a few tenths of a percentage around $555^{\circ} \mathrm{C}$ reflects the transformation of quartz (passage from $\alpha$ phase to $\beta$ phase) as we have just observed in ATD; the reversibility of this phenomenon on cooling, however, not being recorded as shown in the figure. The withdrawal from $800^{\circ} \mathrm{C}$ and $850^{\circ} \mathrm{C}$ shows a first setback after $900^{\circ} \mathrm{C}$ and mainly after $1000^{\circ} \mathrm{C}$. This phenomenon is therefore recorded at low temperatures, thus exhibiting a markedly greater final shrinkage with a rate of 14.4. The shrinkage between $930^{\circ} \mathrm{C}$ and $1000^{\circ} \mathrm{C}$ is related to the structural reorganization of metakaolinite [14], this is generally associated with an increase in the density of the skeleton without elimination of porosity. A large shrinkage is observed after $1000^{\circ} \mathrm{C}$, due to the densification corresponding to the sintering of LON1. The rapid sintering observed suggests the formation of a significant amount of viscous flux. This flow would then be characterized by a viscosity low enough to lead to creep under the effect of pressure gradients generated by 


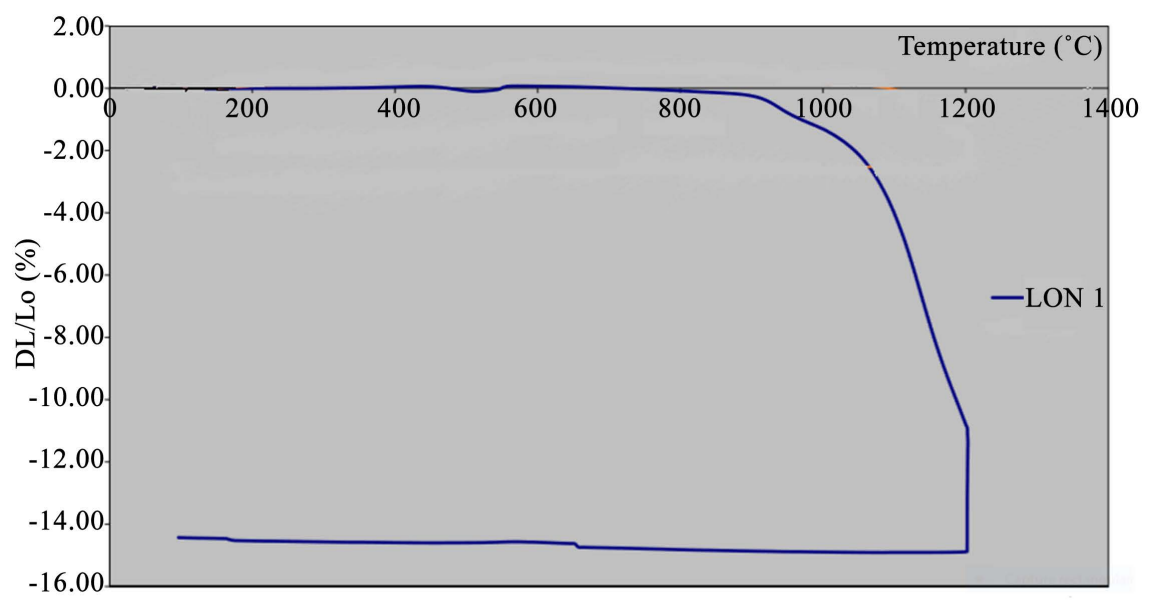

Figure 5. LON1 dilatometric analysis curve.

surface tensions and curvatures between the grains [18]. The dilatometric curve shows that this clay cannot be fired at low temperature around $930^{\circ} \mathrm{C}$.

\subsection{Chemical Analysis}

The results obtained are shown in Table 2 .

The $\mathrm{Al}_{2} \mathrm{O}_{3} / \mathrm{SiO}_{2}$ ratio of LON1 is 0.30 provides information on the material's permeability to moisture. The greater this ratio, the greater the permeability does not change [19]. This value obtained shows that LON1 is very permeable clay. This permeability can be justified by the presence of illite identified in XRD. The iron oxides present, in large quantities $(6.93 \%)$ can cause staining of ceramic products [14]. XRD did not reveal the presence of a characteristic iron peak, which suggests that the iron in LON1 is found in the structure of clay species. The large quantity of iron oxides shows that this clay can be used as energetic fluxes which in addition make the materials conductive of heat, resulting in a decrease in the firing temperature [19]. The percentage sum of oxides, sodium and potassium in LON1 is 2.42; accepted value for the use of ceramic clays as a flux [14].

The percentage of titanium oxides in LON1 (1.16\%) is high, the peak of anatase not observed in the X-ray spectrum may be masked by the peak of kaolinite.

\subsection{SEM and EDS Spectra of Raw LON1 Samples}

Figure 6 and Figure 7 show the images obtained by scanning electron microscopy coupled to the EDX of LON1.

The observation of Figure 6 shows that the clay particles are in the form of platelets in sheets which is in agreement with the results of the XRD which revealed the presence of two types of phyllosilicates. We distinguish the classical flattened accordion shape of kaolinite as observed by Kanon for poorly crystallized kaolinite [20]. The observation of white color aggregate confirms the presence of quartz identified in IR spectrum and in DRX of LON1.

Figure 7 gives the EDS results of LON1. Chemical elements such as: Silicon $(\mathrm{Si})$, Aluminum $(\mathrm{Al})$, Iron $(\mathrm{Fe})$, potassium $(\mathrm{K})$, magnesium $(\mathrm{Mg})$, phosphorus 


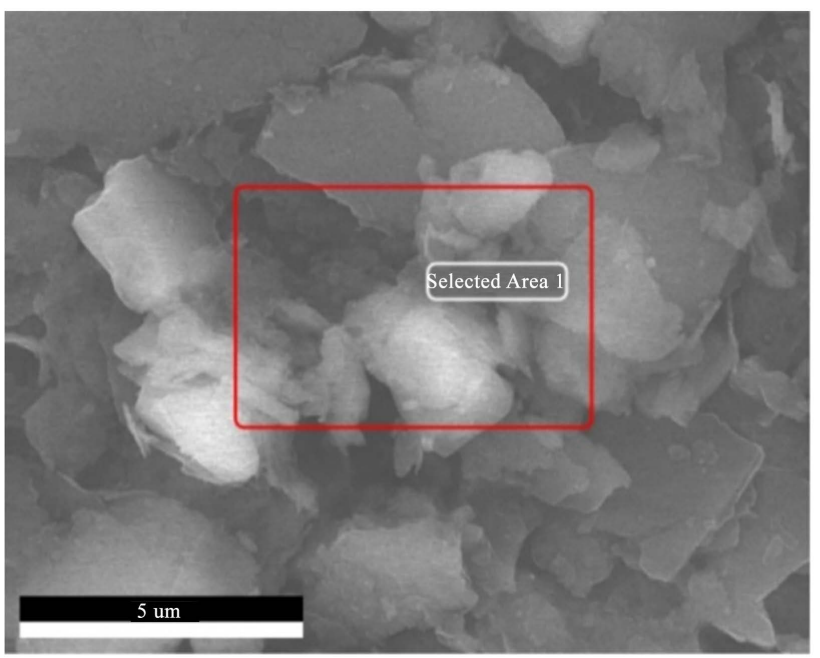

Figure 6. Observation of LON1 with SEM.

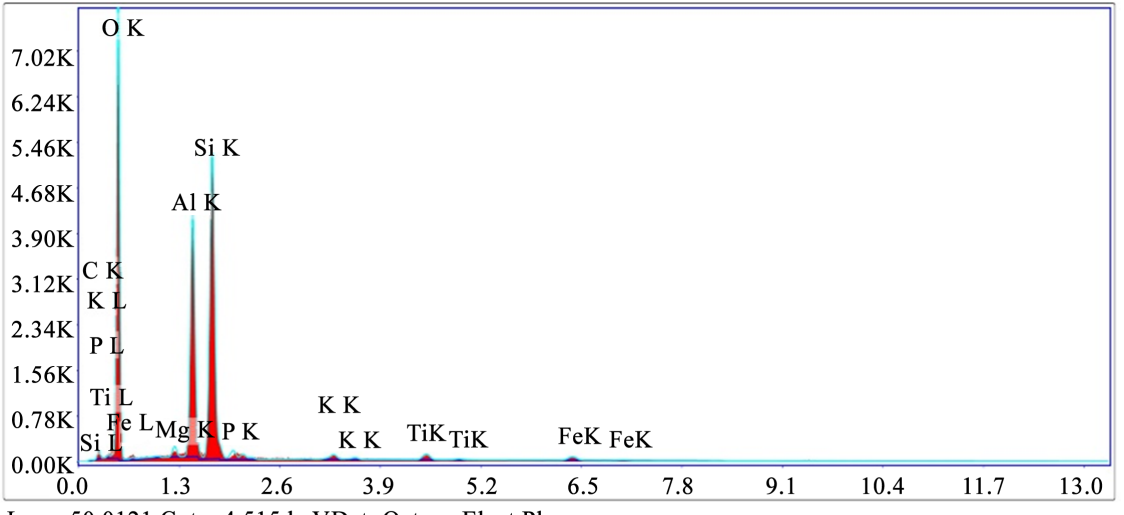

Lsec: 50.0121 Cnts 4.515 keVDet: Octane Elect Plus

Figure 7. EDS spectrum of LON1.

Table 2. Chemical composition of LON1.

\begin{tabular}{ccccccccccccc}
\hline Sample & $\mathrm{SiO}_{2}$ & $\mathrm{Al}_{2} \mathrm{O}_{3}$ & $\mathrm{Fe}_{2} \mathrm{O}_{3}$ & $\mathrm{MnO}$ & $\mathrm{MgO}$ & $\mathrm{CaO}$ & $\mathrm{Na}_{2} \mathrm{O}$ & $\mathrm{K}_{2} \mathrm{O}$ & $\mathrm{TiO}_{2}$ & $\mathrm{P}_{2} \mathrm{O}$ & PF & Total \\
\hline LON1 & 60.97 & 18.53 & 6.93 & $<\mathrm{LD}$ & 0.90 & $<\mathrm{LD}$ & 0.03 & 2.39 & 1.16 & $<\mathrm{LD}$ & 8.87 & 99.88
\end{tabular}

$(\mathrm{P})$, carbon $(\mathrm{C})$, titanium $(\mathrm{Ti})$ and oxygen $(\mathrm{O})$ are present, which is in agreement with the results of the chemical analysis. The strong presence of Oxygen $(\mathrm{O})$ and Potassium (K) may be due to the presence of illite in LON1. The presence of carbon is certainly due to organic matter.

\subsection{Particle Size Analysis}

Figure 8 illustrates the particle size curve of LON1.

The particle size curve thus obtained allowed us to obtain the distribution of particles shown in Table 3.

In view of the results obtained, we can say that LON1 is a soil very rich in silt. The results of the particle size analysis allowed us to position LON1 in the Texture triangle (Figure 9). 


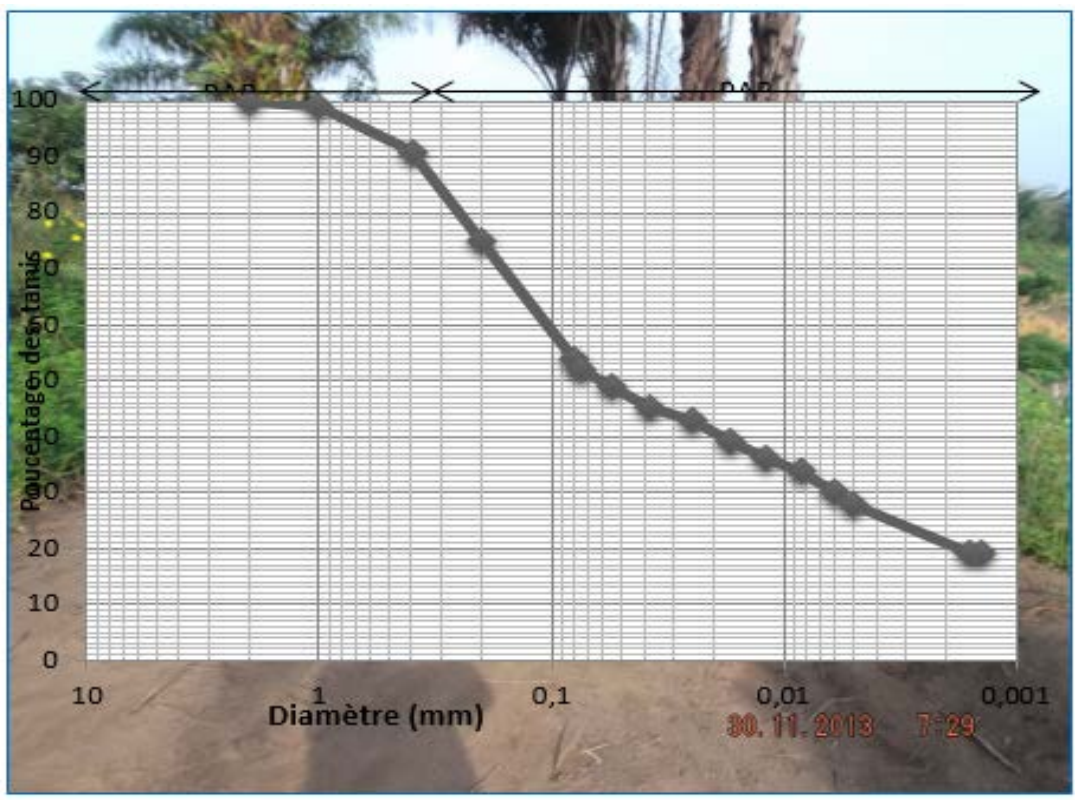

Figure 8. Particle size curve of LON1.

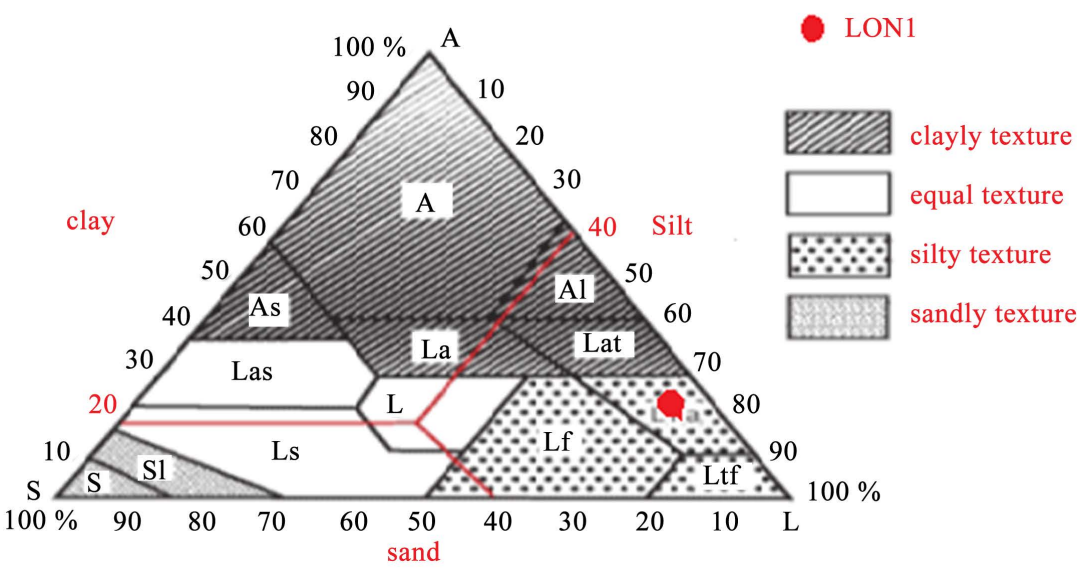

Figure 9. Positioning of LON1 in the Texture triangle.

Table 3. Particle size analysis of LON1.

\begin{tabular}{|c|c|c|c|}
\hline Sample Particuls & Clay $<2 \mu \mathrm{m}$ & $\begin{array}{c}\text { Silt } \\
2-50 \mu \mathrm{m}\end{array}$ & $\begin{array}{l}\text { Fines sands } \\
50-200 \mu \mathrm{m}\end{array}$ \\
\hline LON1 & $25 \%$ & $70 \%$ & $5 \%$ \\
\hline
\end{tabular}

Observation of this triangle shows that LON1 is found in the area of a soil with a silty texture. By positioning LON1 in the Winkler triangle (Figure 10).

LON1 is not found in any brick manufacturing area. By also positioning LON1 in the Shepard triangle (Figure 11).

We find that LON1 is in the low frequency area.

\subsection{ATTERBERG Limits}

Table 4 gives the results of the ATTERBERG limits of LON1. 


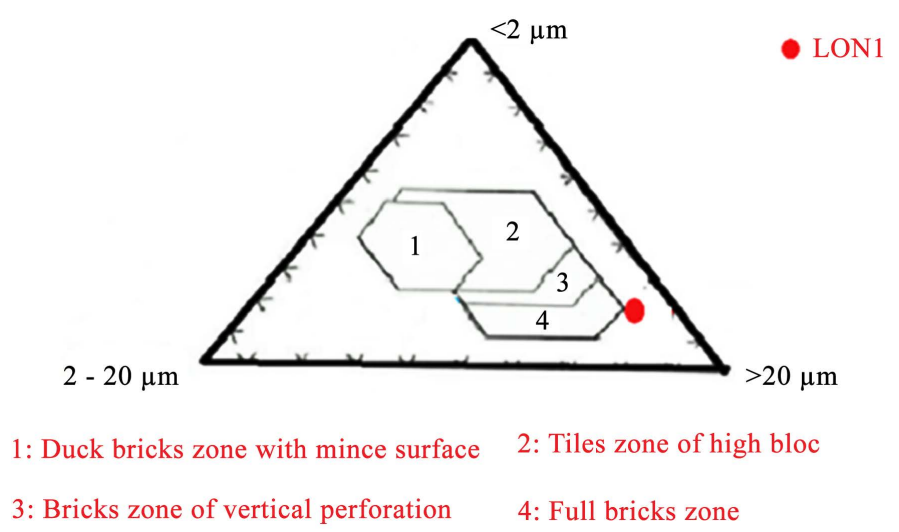

Figure 10. Positioning of LON1 in the Winkler diagram.

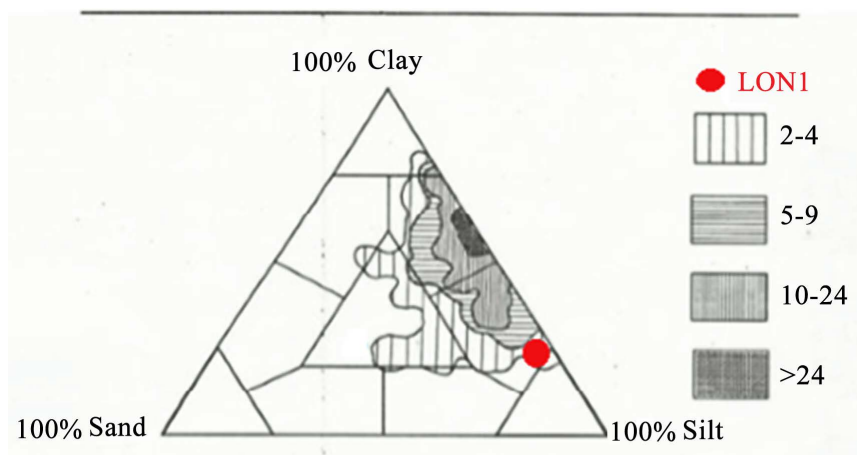

Use frequency

2-4: weak use frequency 10-24: strong use frequency

5-9: fair use frequency $>24$ : very strong use frequency

Figure 11. Positioning of LON1 in the Shepard diagram.

Table 4. ATTERBERG limits of LON1 Limits.

\begin{tabular}{|c|c|c|c|}
\hline Samples Limits & liquidity Limit & Plasticity Limit & liquidity Indice \\
\hline LON1 & $41.5 \%$ & $26.6 \%$ & $17.9 \%$ \\
\hline
\end{tabular}

The results of ATTERBERG Limits of LON1 allowed us, while using the Casagrande diagram (Figure 12), to give the classification of LON1.

LON1 is found in the zone corresponding to the section of moderately compressible inorganic silts and organic silt. The moderately compressible inorganic clays section of LON1 can be explained by its high percentage of silt, since its mineralogical composition consists of illite, which has in its structure the presence of alkalis and alkaline earths. The results of ATTERBERG Limits also allowed us, using the fecundability map (Figure 13), to predict molding properties and soil shrinkage based on criteria related to soil plasticity.

\subsection{Specific Surface}

The results are reported in Table 5. 


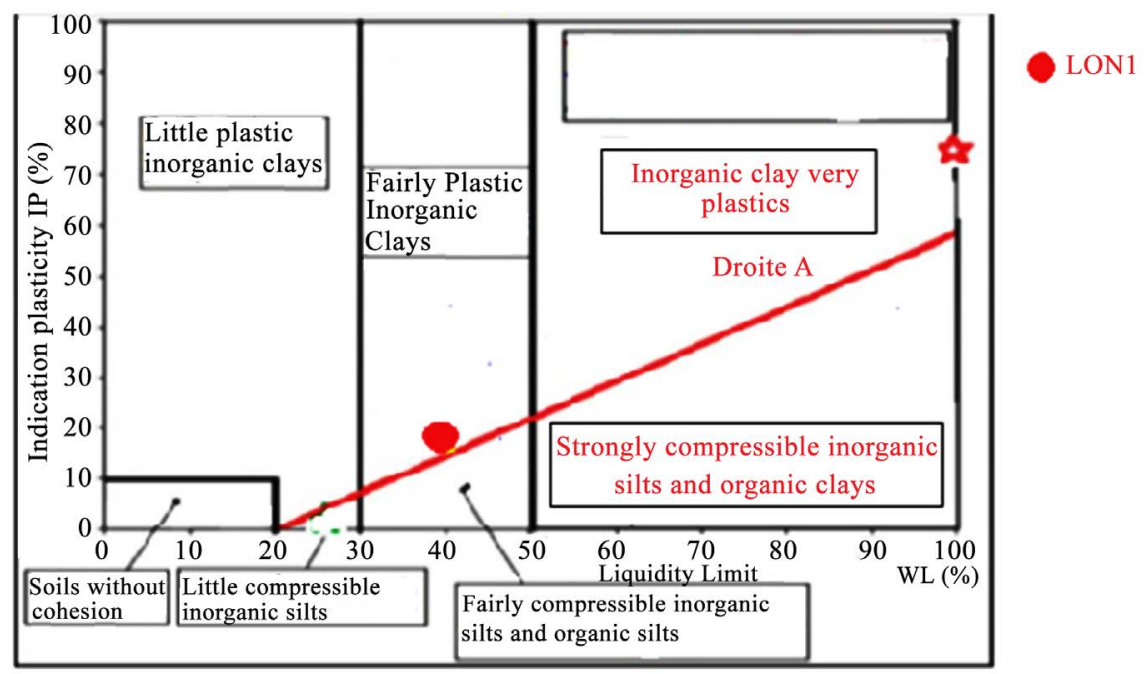

Figure 12. Positioning of LON1 in the casagrande baque.

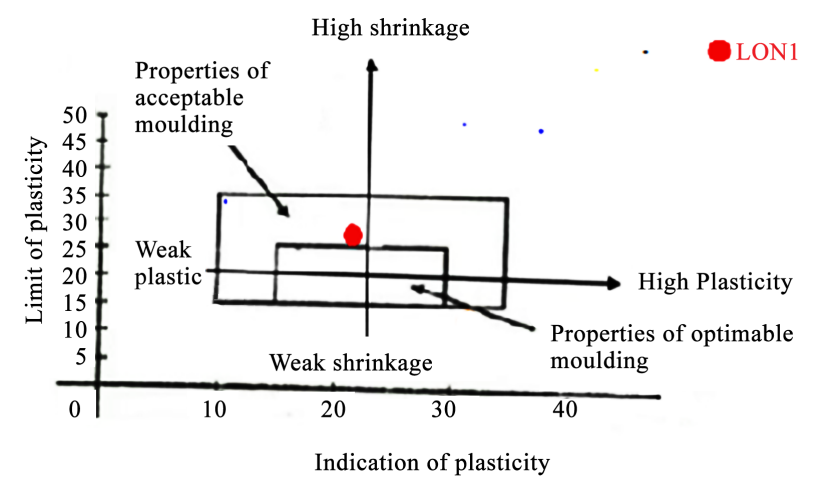

Figure 13. Positioning of LON1 in the card.

Table 5. BET specific surface area of LON1 and LON2.

\begin{tabular}{cc}
\hline Sample & BET Specific surface $\left(\mathrm{m}^{2} / \mathrm{g}\right)$ \\
\hline LON1 & 15.5 \\
\hline
\end{tabular}

The value of the specific surface area thus obtained is characteristic of a kaolinite [21]. Kaolinite therefore represents the most abundant mineral in LON1.

\subsection{Linear Shrinkage during Firing of Fired Bricks}

Figure 14 represents the linear shrinkage of the test pieces obtained.

The results obtained show that the shrinkage increases as a function of the cooking temperature. The high shrinkage of LON1 can be explained by the large amount of alkali and alkaline earth oxides and iron oxides, leading to an increase in the liquid phase during sintering. The significant amount of viscous flux would be characterized by creep under the effect of pressure gradients generated by surface tensions and curvatures between grains causing greater densification generally involving greater linear firing shrinkage[21]. This high retention is in agreement with the result obtained from dilatometry. LON1 alone cannot be 


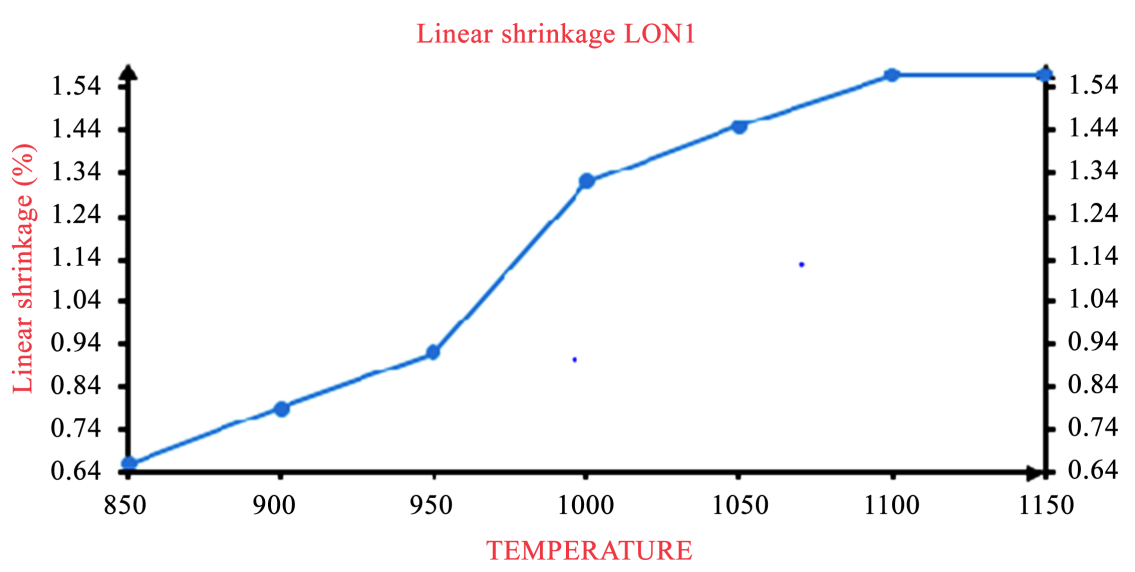

Figure 14. Linear shrinkage curve during firing of LON1.

used in the manufacture of fired bricks, the addition of additives or other clays will be necessary to reduce its shrinkage [22] [23].

\subsection{Water Absorption Rate}

Figure 15 shows the absorption rate of the test pieces obtained after firing LON1.

Analysis of the results obtained shows that the absorption rate of LON1 decreases with increasing temperature. According to Dondi, the rate of fusible material does not provide sufficient flux to improve densification and reduce pores [24]. This result is in agreement with the high silt and clay contents revealed by the particle size analysis. The loamy clayier the soil, the more water it takes to make it plastic. Using less water would reduce the friction between the grains less and also reduce the pores in the bricks less. Blanchard and his collaborators mentioned in their research work on silicate ceramics that the open porosity after firing of terracotta (briquettes, tiles, tiles, etc.) between $950^{\circ} \mathrm{C}$ and $1150^{\circ} \mathrm{C}$ should be between $10 \%$ and $25 \%$ [14]. The sample studied has values greater than $25 \%$. This clay cannot be used in the manufacture of fired bricks. The addition of an adjuvant would be important to improve the absorption values of LON1.

\subsection{Mechanical Resistance to Bending}

Figure 16 represents the values of Mechanical resistance to bending.

The results obtained show that the mechanical flexural strength increases up to a temperature of $1000^{\circ} \mathrm{C}$ and then decreases at a temperature of $1150^{\circ} \mathrm{C}$. The increase in the values of mechanical strength can be explained by the presence of sodium and potassium oxides in LON1 which provide fusible material, thus causing the consolidation of the grains of sand. The decrease in mechanical flexural strength can be explained by a more homogeneous distribution of the porous network within the clay matrix and in particular the formation of a new crystalline phase [21]. The mechanical resistance values obtained compared to 
Rate of absorption of LON1

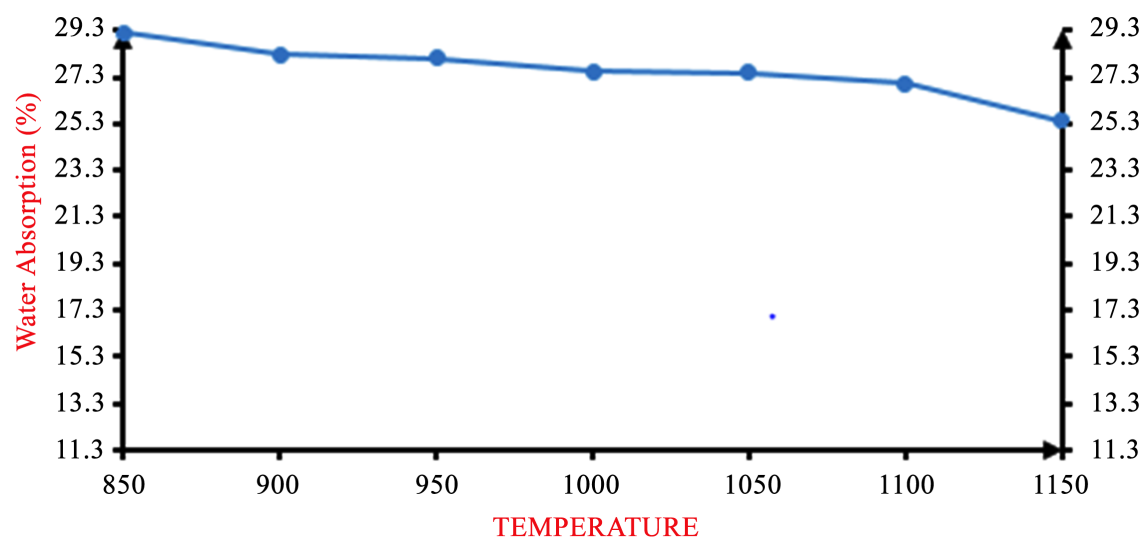

Figure 15. LON1 absorption rate curve.

Flexion mechanical resistance of LON1

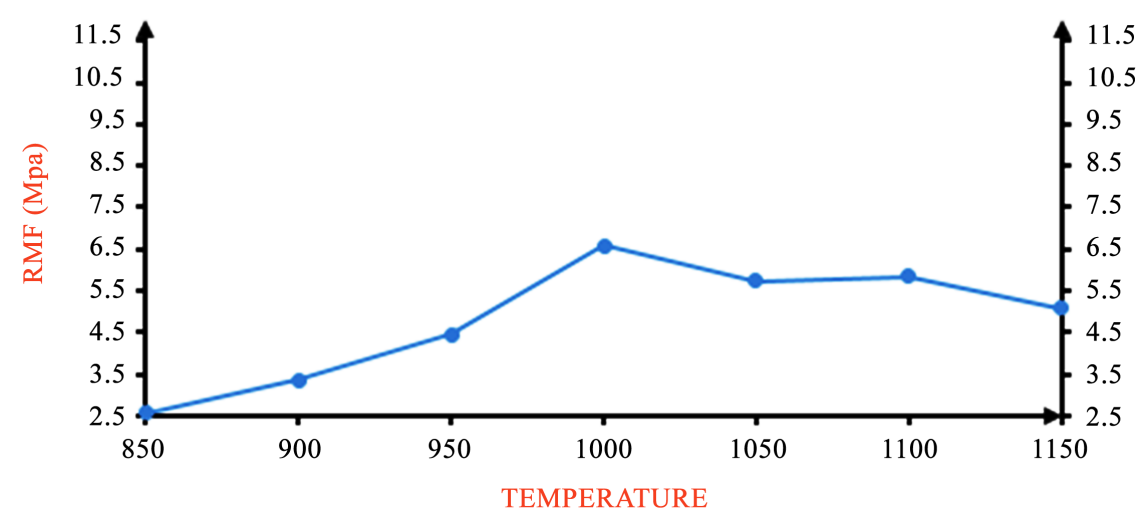

Figure 16. Mechanical flexural resistance curve of LON1.

European standards are low. The low values can be explained by the particle size composition. In fact, silts, the majority fractions in LON1, have almost no cohesion between the particles. On the other hand, the fractions clays less represented in LON1 than the silts, make up the finest fraction of soils (less than two microns) do not have the same characteristics as silts and sand. Each clay particle is surrounded by a film of water that is absorbed very strongly. This gives the clay its cohesion and most of its mechanical strength. The clay therefore gives the finished products its cohesion and acts as a bond between the coarser elements that make up the skeleton [14].

\subsection{Mechanical Resistance to Compression}

Figure 17 shows the mechanical resistance to compression.

The curve obtained shows that between $850^{\circ} \mathrm{C}$ and $1050^{\circ} \mathrm{C}$. There is an increasing function with the cooking temperature and between $1050^{\circ} \mathrm{C}$ and $1150^{\circ} \mathrm{C}$. a decreasing function with the cooking temperature. The increase in this parameter is more pronounced from the cooking temperature of $1050^{\circ} \mathrm{C}$. For this material, the temperature of $1050^{\circ} \mathrm{C}$ represents this limit of mechanical 


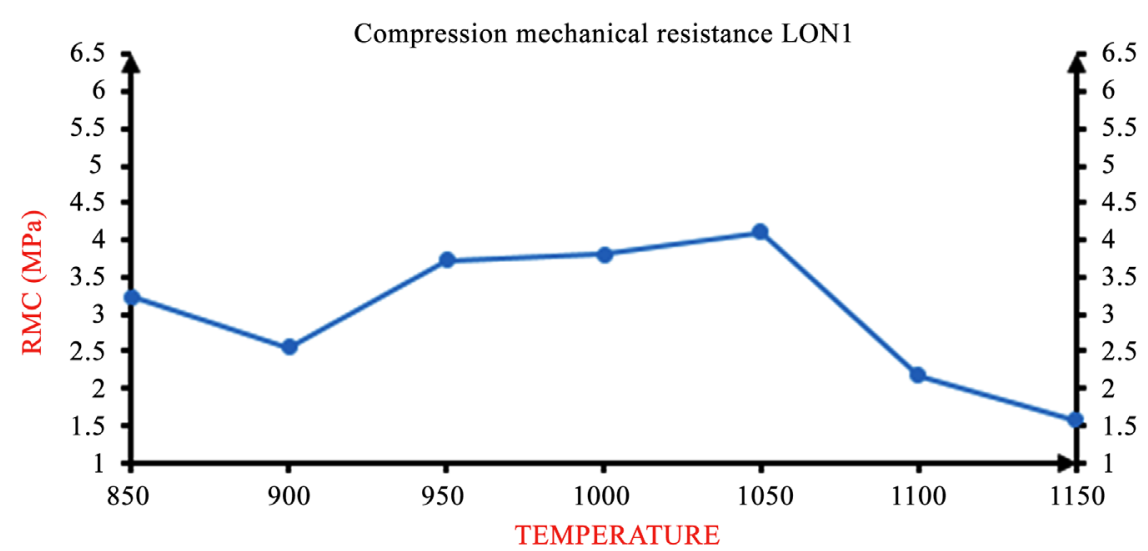

Figure 17. Curve of mechanical resistance to compression of LON1.

resistance to compression. The strong decrease in the mechanical resistance in compression observed from the firing temperature of $1050^{\circ} \mathrm{C}$ makes it possible to formulate the hypothesis of the distribution and the nature of the main crystalline phases present in the skeleton of the fired material [14]. In general, the values of mechanical resistance to compression are low in LON1. This can be explained by higher values of absorption rate as a result of porosity.

\section{Conclusion}

This work had for general objective, the characterization and the valorization of clay taken in Londéla-kayes. Its specific objectives were to carry out a mineralogical characterization and to study the technological properties in order to provide the necessary answers linked to the breakage of bricks made by rural populations. To carry out this study, we used as characterization methods: XRD, IR, ATD/ATG, SEM/EDS, specific surface area by BET method, chemical analysis and geotechnical analyzes. We evaluated the technological properties by linear shrinkage, absorption rate, mechanical resistance to bending and compression. The results of characterization revealed that this soil exhibits kaolinite and illite as clay minerals. This clay can be fired at a low temperature around $930^{\circ} \mathrm{C}$. Analysis of different ceramic tools has shown that this soil has a low frequency to be used in ceramic. The addition of adjuvants would therefore be necessary to improve these geotechnical properties. The results of technological properties compared to standards have shown that this clay cannot be used in the manufacture of fired bricks. The high shrinkage observed in this clay would therefore be the cause causing the breakage of the fired bricks. We plan to continue this study by adding an adjuvant to the Londela-kayes clay to correct this shrinkage in order to obtain products that meet the requirements of the fired brick manufacturing standards.

\section{Conflicts of Interest}

The authors declare no conflicts of interest regarding the publication of this paper. 


\section{References}

[1] Association Internationale Pour l'Étude des Argiles, Newsletter n³2, February 1996.

[2] Sayouba, K., François, O., Bétaboalé, N., Adamah, M., Jean, C.B. and François, Z., (2019) Évaluation des propriétés thermo-hydro-mécaniques des briques en terre compressée (BTC) issues de la carrière de Matourkou, Burkina Faso. Afrique Science, 15, 12-22.

[3] Baron, A.B., Lonvier, J., Millet, J., Sierra, R. and Voinovitch, I. (1971) L'analyse minéralogique des sols argileux. Eyrolles, Paris, 50 p.

[4] Diamouangana, M.F.Z., Moutou, J.M., Matini, L., Mongo, O.F. and Kouhounina, L.M. (2019) Synthesis of an Inorgano-Clay Complex from Loukolela Clay and Application in the Adsorption of Humic Matter. International Research Journal of Environmental Sciences, 8, 12-20.

[5] Moutou, J.M., Loubaki, R., Nsongo, T. and Foutou, P.M. (2019) Characterization and Technological Properties of Two Clay Soils in Republic of Congo. Research Journal of Material Sciences, 7, 1-10.

[6] Moutou, J.M., Foutou, P.M., Matini, L., Banzouzi Samba, V., Diamouangana Mpissi, Z.F. and Loubaki, R. (2018) Characterization and Evaluation of the Potential Uses of Mouyondzi Clay. Journal of Minerals and Materials Characterization and Engineering, 6, 119-138. https://doi.org/10.4236/jmmce.2018.61010

[7] Moutou, J.M., Bibila Mafoumba, C., Matini, L., Ngoro Elenga, F. and Kouhounina, L. (2018) Characterization and Evaluation of the Adsorption Capacity of Dichromate Ions by a Clay Soil of Impfondo. Research Journal of Chemical Sciences, 8 , $1-14$.

[8] Moutou, J.M., Mbedi, R., Elimbi, A., Njopwouo, D., Yvon, J., Barres, O. and Ntekela, H.R. (2012) Mineralogy and Thermal Behaviour of the Kaolinitic Clay of Loutété (Congo-Brazzaville). Research Journal of Environmental and Earth Sciences, 4, 316-324.

[9] Carignan, J., Hild, P., Mevelle, G., Morel, J. and Yeghicheyan, D. (2001) Routine Analyses of Trace Elements in Geological Samples Using Flow Injection and Low Pressure On-Line Liquid Chromatography Coupled to ICP-MS: A Study of Geochemical Reference Materials, BR, DR-N, UB-N, AN-G and GH. Geostandards Newsletter, 25, 187-198. https://doi.org/10.1111/j.1751-908X.2001.tb00595.x

[10] NF P 94-056 et NF P 94-057(1993) Détermination de l'analyse granulométrique. AFNOR.

[11] NF P 94-051 NF P 94-051 (1993) Détermination des limites d'Atterberg. AFNOR.

[12] Rouquerol, F., et al. (2003) Texture des matériaux pulvérulents ou poreux, groupe des solides divisés du MADIREL, Centre national de la recherche scientifique, université de Provence France.

[13] NBN EN 196-1 et EN 772-1(1993) Détermination de la résistance mécanique. AFNOR.

[14] Wetshondo Osomba, D. (2012) Caractérisation e valorisation des matériaux argileux de la Province de Kinshasa (RD Congo). Thèse de docteur ingénieur, Université de Liège (Belgique), 1-341.

[15] Van, O. and Fripiat, J.J. (1979) Data Handbook for Clay Materials and Other Non-Metallic Minerals. Pergamon Press, Oxford.

[16] Tchakoute, H., Kouamo, J.A., Mbey, A., Elimbi, B.B., Kenne, D. and Njopwouo, D. (2013) Synthesis of Volcanic Ash-Based Geopolymer Mortars by Fusion Method: 
Effects of Adding Metakaolin to Fused Volcanic Ash. Ceramics International, 39, 1613-1621. https://doi.org/10.1016/j.ceramint.2012.08.003

[17] Brunauer, S. (1943) The Adsorption of the Gases and Vapors Physical Adsorption. Princeton University Press, Princeton, $511 \mathrm{p}$.

[18] Pialy, P. (2009) Etude de quelques matériaux argileux du site de Lembo (Cameroun): Minéralogie, comportement en frittage et analyse des propriétés d'élasticité. $\mathrm{PhD}$ Thesie, De l'Université de Limoges No7, 78.

[19] Qlihaa, A., Dhimni, S., Melrhaka, F., Hajjaji, N. and Srhiri, A. (2016) Caractérisation physico-chimique d'une argile Marocaine [Physico-Chemical Characterization of a Morrocan Clay]. Journal of Materials and Environmental Science, 7, 1741-1750.

[20] Zangue, A.H. (2012) Adsorption of Heavy Metals Used by Alluvial Clays from the Extreme-North Cameroon. Doctoral Thesis in Geosciences, University of Lorrraine.

[21] Jasmund, K. and Lagaly, G. (1992) La capacité d'adsorption de bentonite activé sur polluant organique et inorganique dans certains déchets liquide industriels. Steinkopff Verlag, Darmstadt.

[22] Sharma, V., Vinayak, H.K. and Marwaha, B.M. (2015) Enhancing Sustainability of Rural Adobe Houses of Hills by Addition of Vernacular Fiber Reinforcement. International Journal of Sustainable Built Environment, 4, 348-358. https://doi.org/10.1016/j.ijsbe.2015.07.002

[23] Lima, S.A., Varum, H., Sales, A. and Neto, V.F. (2012) Analysis of the Mechanical Properties of Compressed Earth Block Masonry Using the Sugarcane Bagasse Ash. Construction and Building Materials, 35, 829-837. https://doi.org/10.1016/j.conbuildmat.2012.04.127

[24] Dondi, M., Raimondo, M. and Zanelli, C. (2014) Clays and Bodies for Ceramic Tiles: Reappraisal and Technological Classification. Applied Clay Science, 96, 91-109. https://doi.org/10.1016/j.clay.2014.01.013 